\title{
Vaccine Wastage: Associated Risk Factors and Policy Implications in the Littoral Region of Cameroon: A Retrospective Data Review
}

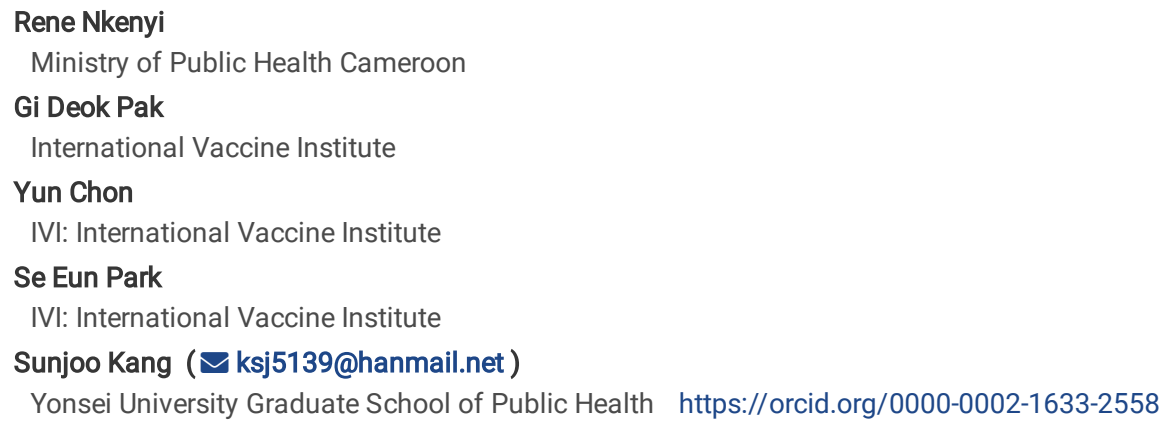

Research

Keywords: Vaccine wastage, Vaccine coverage, Rural, Urban, Seasonality, vaccine types, risk factors, Cameroon

Posted Date: June 18th, 2021

DOI: https://doi.org/10.21203/rs.3.rs-605772/v1

License: (c) (7) This work is licensed under a Creative Commons Attribution 4.0 International License. Read Full License 


\section{Abstract}

Introduction: Immunization is an effective preventive health intervention. In Cameroon, the Expanded Program on Immunization aims to vaccinate children under five years old for free, but vaccination coverage has consistently remained below the national target. Vaccines are distributed based on the target population size, factoring in wastage norms. However, vaccine wastage rates (VWR) may differ among various settings. Our study aimed to assess vaccine wastage for different site settings, seasonality, and vaccine types in comparison to vaccination coverage. As the government of Cameroon continuously seek to improve and vaccination coverage and vaccine wastage, an investigation into why vaccines are being wasted may provide solutions to minimize it occurrences.

Methods: Retrospective data on immunization and vaccine wastage covering 2016 and 2017 in the Littoral Region, Cameroon, were collected. Health districts were classified as urban or rural, seasonality categorized as rainy or dry season, and vaccine types were grouped into liquid, lyophilized, oral, and injectable. VWR and vaccination coverage rates (VCR) were calculated, and the vaccine waste factor was investigated.

Results: From 2,851,527 doses, children made up 2,640,077 in 2016 and 2017. VWR was the highest in the Bacillus Calmette-Guérin (32.19\%) vaccine, followed by measles and rubella (19.05\%) and yellow fever (18.34\%) vaccines. Single-dose vaccine vials exhibited lower VWR than multi-dose vials. February and November experienced a decrease in the VCR. A negative correlation between VCR and VWR was presented. The VWR for most vaccines was higher during the dry season and remained persistently higher in rural than in urban districts.

Conclusion: While the government of Cameroon has consistently been seeking to improve vaccination coverage in recent years by reducing vaccine wastage, understanding risk factors associated to vaccine wastage and coverage is essential for the immunization programs. Reasons for vaccine wastage were multifaceted: limited social infrastructure, cold chain, awareness of immunization, vaccine demand forecasting, and efforts to increase vaccination coverage. To achieve immunization targets, improved forecasting of vaccine demand is essential. Further studies on vaccine wastage and immunization coverage across Cameroon are needed for a comprehensive landscape analysis of immunization programs in Cameroon.

\section{Background}

Immunization is strongly recommended by the global medical community as an effective preventive medicine to protect children and adults against infectious diseases $(1,2)$. Although infectious diseases affect countries worldwide, the burden is higher in many low and middle-income countries, where vaccinepreventable diseases remain one of the major causes of child morbidity and mortality due to low vaccination coverage (3-5). Vaccination coverage also differs within countries, between rural and urban settings, whereby rural areas typically exhibit lower vaccination coverage rates (VCR) (2).

The availability of vaccines and vaccination-related commodities is an important factor that influences vaccination coverage. However, in resourceconstrained countries, with often limited resources, $(6,7)$, effective vaccine management and utilization is critical in ensuring a regular supply of vaccines, safeguarding national vaccine security, and monitoring costs associated with immunization programs (8). This is further emphasized as the number of new vaccine introductions in developing countries has increased in recent years, coupled with the high pricing of new vaccines $(6,9,10)$. It has been argued that with newer vaccines for children, cost saving may not be possible at current prices unless the indirect costs to parents caring for a sick child are considered in addition to the direct costs of medical care (11). The importance of minimizing vaccine wastage without compromising vaccination coverage can be a challenge as recommendations to reduce missed opportunities to vaccinate may contradict efforts to reduce vaccine wastage (6), especially if the policy is not clearly explained to health personnel involved in immunization programs.

In 1997, the World Health Organization (WHO) officially stated that $43 \%$ of vaccines delivered to developing countries were wasted due to poor infrastructure (12). Similarly, aggregated national statistics also show disparities in vaccine waste at a local level, such as rural-urban differences (13), inextricably associated with various challenges concerning infrastructure capacity. Other factors such as low quality of monitoring and tracking of vaccination programs (14), parents' objection or disagreement with vaccination, concerns about vaccine safety, accessibility to health facilities such as walking distances, waiting time in health facilities, low educational level of the local population including residents and health workers, population density, and logistical challenges to conducting vaccination programs contribute to vaccine wastage in both rural and urban settings (15-17).

In Cameroon, the Expanded Program on Immunization (EPI) began in 1976 as a coordinated pilot project of the Organization of Coordination for the Control of Endemic Diseases in Central Africa, which subsequently became operational nationwide in 1982 (18). The national EPI aims to prevent, control, and eliminate or eradicate vaccine-preventable diseases. Following the Declaration of the Reorientation of Primary Health Care in 1993, the EPI activities were integrated into the Minimum Package of Activities of health facilities nationwide and were given to children free of charge with an approach toward vaccination as a fundamental right of every child (18). Immunization coverage in Cameroon has been witnessing a gradual increase over the past decades, but it still falls short of the national target with documentation of missed or incomplete vaccination of eligible children (19). Several reasons explain this, including uptake of national EPI programs by the general population and challenges related to vaccine logistics and management of vaccination programs (20), which aims to not only increase the overall national vaccination coverage but also reduce vaccine wastage (21).

Immunization coverage is related to vaccine wastage as it translates to the availability of vaccines for use, especially in areas with poor access to vaccine storage facilities $(6,7)$. Even when accessibility to the vaccine storage facilities is guaranteed, high vaccine wastage increases the cost of immunization programs, as vaccine waste factors need to be considered when forecasting the number of vaccine doses. The government of Cameroon has consistently been seeking to improve vaccination coverage in recent years by reducing vaccine wastage (Table 1) (18). 
Table 1

Vaccination coverage and vaccine wastage rate targets in Cameroon in 2017

\begin{tabular}{|c|c|c|c|}
\hline Vaccine & Targeted coverage (\%)1 & Targeted wastage rate (WR) (\%) ${ }^{1}$ & WHO acceptable WR (\%) ${ }^{2}$ \\
\hline $\mathrm{BCG}^{3}$ & 89 & 25 & 50 \\
\hline $\mathrm{OPV}^{4}$ & 89 & 10 & 10 \\
\hline $\mathrm{IPV}^{5}$ & 79 & 10 & 15 \\
\hline DPT-HepB-Hib 3rd dose ${ }^{6}$ & 89 & 6 & 15 \\
\hline $\mathrm{PCV}^{7}$ & 89 & 3 & 5 \\
\hline ROTA $^{8}$ & 82 & 5 & 5 \\
\hline $\mathrm{MR}^{9}$ & 89 & 25 & 25 \\
\hline $\mathrm{YF}^{10}$ & 89 & 25 & 25 \\
\hline \multicolumn{4}{|c|}{${ }^{1}$ Source: District Vaccination Data management Tool for Littoral Region (23) } \\
\hline \multicolumn{4}{|c|}{2 Source: Vaccines and Biologicals. Monitoring vaccine wastage at country level. Guidelines for program managers. WHO; 2005 (27 } \\
\hline \multicolumn{4}{|c|}{${ }^{3}$ BCG: Bacillus Calmette-Guérin } \\
\hline \multicolumn{4}{|l|}{4 OPV: Oral Polio Vaccine } \\
\hline \multicolumn{4}{|c|}{${ }^{5}$ IPV: Inactivated Polio Vaccine } \\
\hline \multicolumn{4}{|c|}{${ }^{6}$ DPT-HepB-Hib (pentavalent): Diphtheria, Pertussis, Tetanus, Hepatitis B and Haemophilus influenza type b (Hib) } \\
\hline \multicolumn{4}{|c|}{7 PCV: Pneumococcal Conjugate Vaccine (PCV) } \\
\hline \multicolumn{4}{|l|}{${ }^{8}$ ROTA: Rotavirus Vaccine } \\
\hline \multicolumn{4}{|l|}{${ }^{9}$ MR: Measles and Rubella } \\
\hline 10 YF: Yellow Fever & & & \\
\hline
\end{tabular}

Vaccines are distributed based on the size of the target population and factoring in some wastage norms. Routine monitoring of vaccine wastage rates (VWR) and utilization of field data in estimating vaccine needs is critical for the adequate management of vaccines for immunization programs. Here, we aimed to estimate VWR in various site settings in the Littoral Region of Cameroon, and further investigate vaccine wastage per season and vaccine types in comparison to VCR for respective vaccines that have been introduced in the region. As the government of Cameroon continuously seek to improve and vaccination coverage and vaccine wastage, an investigation into why vaccines are being wasted may provide solutions to minimize it occurrences especially a just a few of such publications exist in the country. The data analyzed and presented will support evidence-based policy decisions and public health measures to improve vaccine management.

\section{Methods}

\section{Study design and inclusion criteria}

Retrospective data collection was conducted and analyzed on immunization records (January 1, 2016, to December 31, 2017,) in the Littoral Region of Cameroon. The records were for children under 5 years old from all 24 health districts in the region. The vaccines targeted for our analyses were Bacillus Calmette-Guérin (BCG), oral polio vaccine (OPV), inactivated polio vaccine (IPV), diphtheria, pertussis, tetanus, hepatitis B, Haemophilus influenza type b (Hib) (pentavalent vaccine; PENTA), pneumococcal conjugate vaccine (PCV), rotavirus vaccine (ROTA), measles-Rubella (MR) vaccine, and yellow fever (YF) vaccine. Records of anti-tetanus vaccine and human papillomavirus (HPV) were excluded from the study as they were not given to children under 5 years of age.

\section{Study setting}

The Littoral Region is one of the most densely populated regions of Cameroon, with an estimated total population of 3.4 million and a surface area of 20,248 $\mathrm{km}^{2}$ (22). There are a total of 189 health districts in Cameroon, of which 24 are in the Littoral Region. These 24 health districts comprised three urban, nine semi-urban, and 12 rural health districts (23). Health districts were classified as rural or urban based on their remoteness. Seasonal patterns were characterized as rainy and dry seasons, covering months from June to November and from December to May, respectively (24). The rainy season is typically associated with poor access to healthcare facilities because of deteriorating road networks and rampant power failure, especially in rural districts. This negatively impacts the vaccine supply chain and increases accidents that result in wastage of unopened vaccine vials during outreach sessions of immunization programs (25). 


\section{Data collection and analysis}

Data were obtained from the government immunization records with authorization from the Ministry of Public Health of Cameroon (Reference $\mathrm{N}^{\mathrm{O}}$ :

814L/MINSANTE/SG/DSF/GTC-PEV). All data collected included dependent variables such as the number of children vaccinated and the number of doses received, in-stock, remaining, used, and wasted; and independent variables that included seasonality (rainy and dry season), setting (urban and rural), types of vaccines (liquid or lyophilized vaccines, and single- or multi-dose vaccines), and route of vaccine administration (oral or injectable vaccines) (Table 2 ). Collected data were entered into an excel-based spreadsheet and analyzed using R version 3.6.0. The number of children vaccinated and the number of vaccine doses used were compared using the chi-square test of independence. The VCR and VWR were calculated using a set of formulas (Table 3 ) (26).

Table 2

Variables used for analyses

\begin{tabular}{|c|c|c|c|c|}
\hline \multicolumn{3}{|l|}{ Variables } & \multirow{2}{*}{$\begin{array}{l}\text { Specifications } \\
\text { Total number of children vaccinated per vaccine }\end{array}$} & \multirow{2}{*}{$\begin{array}{l}\text { Remark } \\
\text { Used to calculate Vaccine Wastage Rate }\end{array}$} \\
\hline \multirow[t]{6}{*}{ Dependent } & \multicolumn{2}{|c|}{ Children vaccinated } & & \\
\hline & \multirow[t]{5}{*}{$\begin{array}{l}\text { Vaccine } \\
\text { doses }\end{array}$} & Doses Received & $\begin{array}{l}\text { Doses received by the health district during the } \\
\text { month }\end{array}$ & \\
\hline & & Doses in stock & $\begin{array}{l}\text { Doses in the health district at the beginning of } \\
\text { each month (Left over doses from the previous } \\
\text { month) }\end{array}$ & \\
\hline & & $\begin{array}{l}\text { Doses remaining (in } \\
\text { sealed vials and not } \\
\text { expired) }\end{array}$ & $\begin{array}{l}\text { Doses left in the health district at the end of the } \\
\text { month }\end{array}$ & \\
\hline & & Doses used & $\begin{array}{l}\text { Calculated from doses received, doses at the } \\
\text { beginning and doses remaining }\end{array}$ & \\
\hline & & Doses wasted & $\begin{array}{l}\text { Calculated as difference between number of } \\
\text { children vaccinated and doses used }\end{array}$ & \\
\hline \multirow[t]{20}{*}{ Independent } & \multirow[t]{2}{*}{ Seasons } & Dry season & From December to May & Favorable conditions \\
\hline & & Rainy season & From June to November & Unfavorable conditions \\
\hline & \multirow[t]{2}{*}{ Setting } & Rural Areas (12 HD) & Poor road networks and electricity supply & Unfavorable \\
\hline & & Urban Areas (12 HD) & Constant power supply and good road networks & Favorable \\
\hline & \multirow{16}{*}{$\begin{array}{l}\text { Vaccines } \\
\text { categories }\end{array}$} & \multirow[t]{5}{*}{ Liquid } & Oral Polio Vaccine & \multirow{4}{*}{$\begin{array}{l}\text { Wastage relatively easily managed through } \\
\text { the Multi-Dose Vial Policy }\end{array}$} \\
\hline & & & DTP-HepB Hib & \\
\hline & & & Pneumococcal Conjugate Vaccine & \\
\hline & & & Inactivated Polio Vaccine & \\
\hline & & & Rotavirus & \\
\hline & & \multirow[t]{3}{*}{ Lyophilized } & Bacillus Calmette-Guérin & \multirow{3}{*}{$\begin{array}{l}\text { Potential for conflict between reduction in } \\
\text { vaccine wastage and Missed Opportunity tc } \\
\text { Vaccinate }\end{array}$} \\
\hline & & & Measles and Rubella & \\
\hline & & & Yellow fever & \\
\hline & & \multirow[t]{2}{*}{ Oral vaccines } & Oral Polio Vaccine & \multirow[t]{2}{*}{ Easily administered } \\
\hline & & & Rotavirus & \\
\hline & & \multirow[t]{6}{*}{ Injectable vaccines } & DTP-HерB Hib & \multirow{6}{*}{$\begin{array}{l}\text { Not easily administered (liable to dose } \\
\text { estimation and reconstitution errors) }\end{array}$} \\
\hline & & & Pneumococcal Conjugate Vaccine & \\
\hline & & & Inactivated Polio Vaccine & \\
\hline & & & Bacillus Calmette-Guérin & \\
\hline & & & Measles and Rubella & \\
\hline & & & Yellow Fever & \\
\hline
\end{tabular}

\section{Results}

\section{Vaccine wastage and vaccination coverage rates}

A total of 2,851,527 doses of vaccines were used in 2016 and 2017 in the Littoral Region of Cameroon to vaccinate 2,640,077 children with BCG, OPV, IPV, PENTA, PCV, MR, and YF vaccines. The total VWR and the vaccine wastage factor during this period were the highest in BCG (172,997/255,125; $32.19 \%)$, followed by MR (148,175/183,042; 19.05\%), YF (153,965/188,533; 18.34\%), and IPV (157,656/191,950; 17.87\%) (Table 4). A negative VWR was exhibited in 
the single-dose vial vaccines, such as PCV and rotavirus, throughout 2016 and 2017. Overall, the vaccine waste patterns in the investigated vaccines remained similar between 2016 and 2017.

Table 4

Wastage rates and factors for different vaccines in the Littoral Region in 2016 and $2017^{1}$

\begin{tabular}{|c|c|c|c|c|c|c|c|c|c|c|c|c|}
\hline \multirow[t]{2}{*}{ Vaccines $^{2}$} & \multicolumn{4}{|l|}{2016} & \multicolumn{4}{|l|}{2017} & \multicolumn{4}{|l|}{ Total } \\
\hline & $\begin{array}{l}\text { Children } \\
\text { vaccinated }\end{array}$ & $\begin{array}{l}\text { Doses } \\
\text { used }\end{array}$ & WR & WF & $\begin{array}{l}\text { Children } \\
\text { vaccinated }\end{array}$ & $\begin{array}{l}\text { Doses } \\
\text { used }\end{array}$ & WR & WF & $\begin{array}{l}\text { Children } \\
\text { vaccinated }\end{array}$ & $\begin{array}{l}\text { Doses } \\
\text { used }\end{array}$ & WR & WF \\
\hline BCG & 88,041 & 128,233 & $31.34 \%$ & 1.0031 & 84,956 & 126,892 & $33.05 \%$ & 1.0033 & 172,997 & 255,125 & $32.19 \%$ & 1.0032 \\
\hline OPV & 347,083 & 360,238 & $3.65 \%$ & 1.0004 & 327,576 & 344,233 & $4.84 \%$ & 1.0005 & 674,659 & 704,471 & $4.23 \%$ & 1.0004 \\
\hline IPV & 84,196 & 102,329 & $17.72 \%$ & 1.0018 & 73,460 & 89,621 & $18.03 \%$ & 1.0018 & 157,656 & 191,950 & $17.87 \%$ & 1.0018 \\
\hline PENTA & 259,277 & 265,547 & $2.36 \%$ & 1.0002 & 241,162 & 253,707 & $4.94 \%$ & 1.0005 & 500,439 & 519,254 & $3.62 \%$ & 1.0004 \\
\hline PCV & 259,079 & 251,142 & $-3.16 \%$ & 0.9997 & 242,642 & 233,048 & $-4.12 \%$ & 0.9996 & 501,721 & 484,190 & $-3.62 \%$ & 0.9996 \\
\hline ROTA & 168,835 & 165,226 & $-2.18 \%$ & 0.9998 & 161,630 & 159,736 & $-1.19 \%$ & 0.9999 & 330,465 & 324,962 & $-1.69 \%$ & 0.9998 \\
\hline MR & 81,642 & 100,052 & $18.40 \%$ & 1.0018 & 66,533 & 82,990 & $19.83 \%$ & 1.0020 & 148,175 & 183,042 & $19.05 \%$ & 1.0019 \\
\hline YF & 81,523 & 99,389 & $17.98 \%$ & 1.0018 & 72,442 & 89,144 & $18.74 \%$ & 1.0019 & 153,965 & 188,533 & $18.34 \%$ & 1.0018 \\
\hline Total & $1,369,676$ & $1,472,156$ & $6.96 \%$ & 1.0007 & $1,270,401$ & $1,379,371$ & $7.90 \%$ & 1.0008 & $2,640,077$ & $2,851,527$ & $7.42 \%$ & 1.0007 \\
\hline
\end{tabular}

1 Source: District Vaccination Data management Tool for Littoral Region (23)

2 Vaccines: BCG: Bacillus Calmette-Guérin, OPV: Oral Polio Vaccine, IPV: Inactivated Polio Vaccine, DPT-HepB-Hib: Diphtheria, Pertussis, Tetanus, Hepatitis B and Haemophilus influenza type b (Hib), PCV: Pneumococcal Conjugate Vaccine (PCV), ROTA: Rotavirus Vaccine, MR: Measles and Rubella, YF: Yellow Fever

WR: Wastage rate; WF: Wastage Factor

Comparative analysis of vaccine wastage and coverage rates showed a negative correlation in most vaccines (Fig. 1). VWR increased each time VCR decreased, except in 2016 between October and November, whereby both vaccination coverage and vaccine wastage rates decreased simultaneously. The vaccination coverage of three vaccines, BCG, IPV, and MR, started high in January but fell immediately in February before increasing again in the following months in both 2016 and 2017. Notably, vaccine coverage declined sharply in October and November for all three vaccines, but especially for BCG immunization in both years, although its coverage rate increased again in December.

\section{Vaccine wastage in rural and urban settings}

The VWR, categorizing vaccines according to their route of administration and form of preservation, was consistently higher in rural health districts than in urban health districts in both years (Fig. 2). Vaccine wastage was significantly different between rural and urban health districts in 2016 and 2017 for all vaccines, except for PCV and rotavirus (Table 5). Notably, the lyophilized vaccines exhibited higher wastage in both rural and urban health districts (Fig. 3).

\section{Seasonality and vaccine wastage rates per types of vaccines}

In 2016, more vaccines were wasted during the dry season in all vaccine categories except the lyophilized vaccines, while in 2017 , more vaccines were wasted during the dry season in all vaccine categories (Fig. 4). In 2016, more lyophilized vaccines (BCG, MR, and YF) were wasted during the rainy season, whereas the liquid vaccines (pentavalent vaccine, OPV, and IPV) were wasted in the dry season (Table 6). Of all the vaccines, the biggest difference in vaccine wastage occurred with IPV in 2017, whereby the VWR in the dry season was $25.15 \%$ higher by over $50 \%$ than in the rainy season (12.16\%) (Table 6). Except for the single-dose vaccines (rotavirus vaccine and PCV) and only in 2016 with insignificant differences in wastage rate between the dry season and the rainy season, the wastage rate of all other vaccines was statistically significantly different between the rainy and dry seasons (Table 6).

\section{Discussions}

To achieve the full effect of immunization, high vaccine coverage and low vaccine wastage are important. High vaccine wastage makes vaccines less available for use, especially in remote areas where access to the central vaccine storage facility is difficult. To avoid compromising any efforts to increase vaccination coverage while minimizing vaccine wastage (26), an appropriate and accurate demand forecasting of vaccines for the immunization target populations and regular monitoring of vaccine waste at all levels is important. The WHO guidelines on VWR per vaccine (27) recommend 50\% VWR for BCG, $10 \%$ for OPV, $25 \%$ for $10-20$ dose vials lyophilized vaccines, $15 \%$ for $10-20$ dose liquid vaccines, and $5 \%$ for single-dose vaccines. Country-specific vaccine procurement and management capacities are essential for achieving such targets. In Cameroon, the targeted VWR (21) under the routine EPI during 2016 and 2017 was influenced by the government's commitment to more resources in the EPI program, such as setting up a comprehensive multiyear plan (28) and the supplementary immunization activities in health districts with poor performance indicators. Such government efforts led to high vaccination coverage in December 2016 and January 2017. 
In the Littoral Region of Cameroon, lyophilized vaccines showed a higher VWR, although within the WHO projected ranges. This finding is similar to that of an existing study in The Gambia (10), which showed higher wastage rates in lyophilized vaccines than in other types of vaccines. The VWR in our study was lower than in a study in Bangladesh (29), where the wastage rate for BCG was nearly $84.9 \%$, followed by the MR vaccine at $69.7 \%$, and PENTA at $44.4 \%$. Notably, the liquid vaccine IPV also showed a high wastage rate (17.9\%). This may be because it was introduced into the EPI in the Littoral Region in June 2015 (30), and wastage was high at the early stage of vaccine introduction as typically experienced in new immunization programs (31). Our study supports the existing literature on lower wastage rates for vaccines that follow the multi-dose vial policy (MDVP), as seen in other studies from the North West Region of Cameroon (32) and Bangladesh (29).

The MDVP recommendation on the use of opened vaccine vials for up to 28 days, provided the storage conditions are favorable (33), is expected to reduce vaccine wastages (34). However, for lyophilized vaccines (BCG, MR, and YF), their usage is limited to only six hours after reconstitution or at the end of the vaccination session whichever comes first, after which they must be discarded irrespective of the doses that have been used in the vial (35). Thus, vaccine wastage is only avoidable in large enough sessions that last for less than six hours. Therefore, lyophilized vaccines have a higher wastage rate than liquid vaccines (OPV, IPV, PENTA, PCV, and rotavirus vaccines).

Understanding the relationship between vaccination coverage and vaccine waste is important to investigate the reason for vaccine wastage. Analyzing these two variables over time would allow a better understanding of the reasons for vaccine wastage. If vaccines are used to vaccinate the target population per the immunization plan and standard operating procedures for adequate vaccine management, wastage should remain at a minimum, and vaccination coverage should increase. Overall, our study showed a negative correlation between vaccination coverage and vaccine wastage, and causality may be multifaceted. A lower vaccination coverage may not necessarily be due to the unavailability of vaccines or high VWR. Conversely, a low vaccination coverage may cause an increase in vaccine wastage as vaccines can remain in health facilities and get damaged, resulting in an insufficient number of vaccines to immunize the target population. This is explicable as leftover vaccines taken to outreach sites may not return to the cold chain in their optimal conditions (36) and may be discarded. Notably, between October and November 2016, the wastage of all vaccines decreased as the coverage also decreased. This may be due to the lower number of available vaccines, or could also be related to adopting strategies that reduce vaccine wastage but compromise vaccination coverage (6). The former is the most likely cause in the Littoral Region, as no BCG was available even at the central vaccine storage facility in Yaoundé during this study period. The lack of a particular vaccine has a demotivating effect on healthcare workers in organizing vaccination sessions, as they will need to reorganize such sessions when the missing vaccine becomes available. Parents are demotivated to come for vaccination if they are aware that the vaccines are lacking.

Rural areas are characterized by a smaller population size that is sparsely distributed, resulting in conditions that favor a high VWR (34). This is the case with the Littoral Region, where over the two years, rural districts had higher VWR. Compared to the urban health districts that mostly employ a fixed vaccination strategy (where children are brought to health facilities for vaccination), in rural districts, an outreach vaccination strategy is typically applied to reach people living in remote areas with limited access to health facilities. Usually, vaccine vials taken out for this strategy do not return to the vaccine storage facilities if the vaccine vial monitors (small stickers that adhere to vaccine vials and change color as the vaccine is exposed to heat, letting health workers know whether the vaccine can be safely used for immunization) are not in place. Furthermore, the possibility of accidents occurring in rural areas leading to unopened vial breakage is more likely than in urban areas, and less skilled personnel may be involved in the immunization activities (34). Not fully understanding the importance of vaccination due to low educational levels of rural populations often results in their negligent behavior toward meeting the vaccination appointment (17). This often leads to wasting open vials, especially in lyophilized vaccines. Notably, such differences in rural and urban vaccine waste were not significant in a study conducted in Gambia (10). This may be due to enhanced vaccine management and high vaccination coverage in Gambia. In the Littoral Region of Cameroon, attempts are being made to resolve the vaccine wastage problem in rural areas and nearby health facilities by planning immunization sessions more strategically, thus, increasing the vaccinated target population size.

The two major seasons, dry and rainy, in Cameroon have a distinctively different effect on immunization activities. Although the dry season is very dusty, it is favorable regarding weather, road conditions and energy supply. During the rainy season, parents are more likely to miss vaccination appointments, which result in increased vaccine wastage, especially for lyophilized vaccines. This is probably why vaccine waste for BCG, MR, and YF was higher during the rainy season in 2016. However, in 2017, the wastage rate for all vaccines was unexpectedly higher in the dry season. This may be due to the higher ambient temperature in 2017, which may have affected vaccines with inadequate cold chains.

In conclusion, investigating vaccine wastage concerning immunization coverage is important to better understand the reasons for VWR and to plan and design better immunization programs that address the identified challenges. To reduce vaccine wastage in the Littoral Region of Cameroon, emphasis should be placed on rural areas during the rainy season (especially for lyophilized vaccines) and the dry season. Better cold chain systems should be put in place by investing in basic social infrastructure, such as adequate energy sources for field vaccine storage capabilities. To address some of the challenges associated with vaccine cold chain management, efforts are underway to develop vaccines that can tolerate extreme temperatures or be out-of-cold chains for a certain time under monitored and controlled conditions (37). This controlled temperature chain (CTC) is an innovative approach to facilitate vaccine management, aimed at reducing vaccine wastage and reaching at-risk vulnerable populations living in remote rural areas or hard to reach areas with limited cold chain conditions and infrastructure. However, this requires the vaccines to be used in a campaign or special strategy setting and that they can tolerate ambient temperatures of at least $+40^{\circ} \mathrm{C}$ for a minimum of three days. The vaccines analyzed in this study are currently not available for CTC usage. Furthermore, capacity building of health workers involved in immunization programs is essential. This could include continued community engagement and sensitization, particularly for the rural population, regarding the importance of vaccination. Finally, increasing the size of immunization sessions by facilitating the transportation of vaccines and personnel close to the target population will reduce open vial vaccine wastage. Considering the diverse geographical and climatic characteristics of Cameroon in general and the Littoral Region in particular, better vaccine forecasting with more realistic wastage rates is recommended to prevent the inappropriate supply of vaccines. Further studies are warranted to generate a more comprehensive analysis of vaccine waste across Cameroon and in dynamic climatic changes. This will allow for more refined policy formulation and customized interventions in various settings. 


\section{Limitations Of The Study}

The study reviewed secondary data. Inherent to secondary data, the accuracy of the result of the study depends on the accuracy with which the data was collected in the first place

\section{List Of Abbreviations}

\begin{tabular}{ll} 
BCG & Bacillus Calmette-Guérin \\
\hline CTC & Controlled Temperature Chain \\
\hline EPI & Expanded Program on Immunization \\
\hline IPV & Inactivated Polio Vaccine \\
\hline MR & Measles and Rubella \\
\hline OPV & Oral Polio Vaccine \\
\hline PCV & Pneumococcal Conjugate Vaccine \\
\hline VCR & Vaccination Coverage Rates \\
\hline VWR & Vaccine Wastage Rates \\
\hline WHO & World Health Organization \\
\hline YF & Yellow Fever
\end{tabular}

\section{Declarations}

Ethics approval and consent to participate

Data were obtained with permission from the Ministry of Public Health, Cameroon. All of the data were processed with anonymity, and only used on the researcher's personal computer, for the purposes of this study. No personal information was provided in this study. The names of the health districts were not used; instead, they were classified as 'rural' and 'urban'. Ethical authorization was obtained from the Yonsei University Health System Institutional Review Board (authorization No: Y-2019-0144).

Consent for publication

Not applicable

Availability of data and materials

Data was obtained with permission from the ministry of public health's data base. Data can be obtained by contacting the Central Technical Group (CTG) of the EPI, Ministry of Public Health, Cameroon

Competing interests

The authors declare that they have no competing interests.

\section{Funding}

The study was not funded

Author contributions

This work was carried out in collaboration with all the authors. RN conducted the literature review and conceptualized the initial research question and study design in discussions with YC and GDP. RN and CT contributed to the data collection. RN and GDP performed the statistical analyses. RN wrote the first draft of this manuscript under the supervision of SEP and SJK. All authors read and approved the final manuscript.

Acknowledgments

We gratefully acknowledge the efforts of Prof. Myung Ken Lee, Director of the Global Health Security Program at the Graduate School of Public Health, Yonsei University, and the entire staff for their support of this study. We also acknowledge the Biostatistics and Data Management Department of the International Vaccine Institute for providing valuable statistical inputs and guidance for this study.

Disclosure

This article is a condensed form of the first author's master's thesis from the Graduate School of Public Health Yonsei University.

\section{References}


1. Lahariya C. A brief history of vaccines \& vaccination in India. Indian J Med Res. 2014; 21.

2. Andre FE, Booy R, Bock HL, Clemens J, Datta SK, John TJ, et al. Vaccination greatly reduces disease, disability, death and inequity worldwide. Bull World Health Organ. 2008; 86(2):140-6.

3. Marin M, Guris D, Chaves S, Schmid S, Seward JF. Prevention of Varicella: recommendations of the Advisory Committee on Immunization Practices (ACIP). 2018. https://www.cdc.gov/mmwr/preview/mmwrhtml/rr5604a1.html. Accessed on 12 July 2019

4. Lim SS, Allen K, Bhutta ZA, Dandona L, Forouzanfar MH, Fullman N, et al. Measuring the health-related Sustainable Development Goals in 188 countries: a baseline analysis from the Global Burden of Disease Study 2015. The Lancet. 2016; 388(10053):1813-50.

5. Turner HC, Thwaites GE, Clapham HE. Vaccine-preventable diseases in lower-middle-income countries. Lancet Infect Dis. 2018; 18(9):937-9.

6. Wallace AS, Willis F, Nwaze E, Dieng B, Sipilanyambe N, Daniels D, et al. Vaccine wastage in Nigeria: An assessment of wastage rates and related vaccinator knowledge, attitudes and practices. Vaccine. 2017; 35(48):6751-8.

7. Patel PB, Rana JJ, Jangid SG, Bavarva NR, Patel MJ, Bansal RK. Vaccine wastage assessment after introduction of open vial policy in Surat municipal corporation area of India. Int J Health Policy Manag. 2015; 5(4):233-6.

8. UNICEF. Vaccine Wastage Assessment. Field assessment and observations from National stores and five selected states of India. 2010. https://www.mofa.go.jp/mofaj/gaiko/oda/seisaku/kanmin/chusho_h24/pdfs/a20-12.pdf. Accessed on 05 September 2019

9. Parmar D, Baruwa EM, Zuber P, Kone S. Impact of wastage on single and multi-dose vaccine vials: implications for introducing pneumococcal vaccines in developing countries. Hum Vaccin. 2010; 6(3):270-8.

10. Usuf E, Mackenzie G, Ceesay L, Sowe D, Kampmann B, Roca A. Vaccine wastage in The Gambia: a prospective observational study. BMC Pub Health. 2018; $18(1): 864$.

11. Scheifele DW. New vaccines and the rising costs of caring. Paediatr Child Health. 2000; 5(7):371-2.

12. Office USGA. Global Health: Factors Contributing to Low Vaccination Rates in Developing Countries. 1999. https://www.gao.gov/products/NSIAD-00-4. Accessed on 08 September 2019

13. Naeem M, Khan MZUI, Adil M, Abbas SH, Khan MU, Khan A, et al. Inequity in childhood immunization between urban and rural areas of Peshawar. J Ayub Med Coll Abbottabad JAMC. 2011; 23(3):134-7.

14. Agarwal S, Bhanot A, Goindi G. Understanding and Addressing Childhood Immunization Coverage in Urban Slums. INDIAN Pediatr. $2005 ; 42: 11$.

15. Ashok A, Brison M, LeTallec Y. Improving cold chain systems: challenges and solutions. Vaccine. 2017; 35(17):2217-23.

16. Okafor IP, Dolapo DC, Onigbogi MO, Iloabuchi IG. Rural-urban disparities in maternal immunization knowledge and childhood health-seeking behavior in Nigeria: a mixed method study. Afr Health Sci. 2014; 14(2):339-47.

17. Nkenyi R, Telep D, Ndip L, Nsagha D. Factors associated to the non-adherence to vaccination appointments in the Ngambe health district, Littoral region, Cameroon: a Case Control Study. Int J Trop Dis Health. 2019; 13; $1-9$.

18. Expanded Program of Immunization. Norms and Standards of the Expanded Program of Immunization Cameroon. 3rd ed. Yaoundé, Cameroon: Ministry of Public Health, Cameroon; 2018.

19. Chiabi A, Nguefack FD, Njapndounke F, Kobela M, Kenfack K, Nguefack S, et al. Vaccination of infants aged 0 to 11 months at the Yaounde Gynaecoobstetric and pediatric hospital in Cameroon: how complete and how timely? BMC Pediatr. 2017;17.

https://www.ncbi.nlm.nih.gov/pmc/articles/PMC5735527/ Accessed on 05 August 2019

20. Palanivel C, Vaman K, Kalaiselvi S, Baridalyne N. Vaccine wastage assessment in a primary care setting in urban India. J Pediatr Sci. 2012 , 4(1):6.

21. Expanded Program of Immunisation District Vaccination Management Tool. Ministry of Public Health, Cameroon; 2017.

22. Littoral region. 2020. http://cvuc.cm/national/index.php/en/administrative-map/region-du-littoral-2?id=143 Accessed on 15 October 2019

23. Gavi country factsheet: Cameroon. (2019) https://www.gavi.org/country/cameroon/ Accessed on 15 October 2019

24. Cameroon Climate: Current Weather and season patterns in Cameroon. (2019) https://www.cameroon-today.com/cameroon-climate.html Accessed on 15 October 2019

25. Kosari S, Walker EJ, Anderson C, Peterson GM, Naunton M, Castillo Martinez E, et al. Power outages and refrigerated medicines: the need for better guidelines, awareness and planning. J Clin Pharm Ther. 2018; 43(5):737-9.

26. Immunization, Vaccines and Biologicals. Monitoring vaccine wastage at country level. Guidelines for programme managers. World Health Organization; 2005; p. 77. https://apps.who.int/iris/bitstream/handle/10665/68463/WHO_VB_03.18.Rev.1_eng.pdf?sequence=1\&isAllowed=y Accessed on 19 July 2019

27. Immunization Module: Vaccine Supply and Stock Management: view as single page. 2019.

https://www.open.edu/openlearncreate/mod/oucontent/view.php?id=53353\&printable=1 Accessed on 19 July 2019

28. MINSANTE. Comprehensive Multiyear plan 2007-2011 of the Expanded Program on Immunization. Minsante Repub Cameroon. 2006 ; 98.

29. Guichard S, Hymbaugh K, Burkholder B, Diorditsa S, Navarro C, Ahmed S, et al. Vaccine wastage in Bangladesh. Vaccine. 2010; 28(3):858-63.

30. DRSPL. Regional Delegation of Public Heath for the Littoral Region, Cameroon. 2017.

31. Tiwari R, Dwivedi S, Swami P, Mahore R, Tiwari S. A study to assess vaccine wastage in an immunization clinic of tertiary care centre, Gwalior, Madhya Pradesh, India. Int J Res Med Sci. 2017; 5(6):2472.

32. Ebong CE, Levy P. Impact of the introduction of new vaccines and vaccine wastage rate on the cost-effectiveness of routine EPI: lessons from a descriptive study in a Cameroonian health district. Cost Eff Resour Alloc. 2011; 9(1):9. 
33. WHO. WHO policy statement: multi-dose vial policy (MDVP): handling of multi-dose vaccine vials after opening. 2014.

https://apps.who.int/iris/handle/10665/135972 Accessed on 22 August 2019

34. Patle L, Adikane H, Dhage D, Surwase K, Gogulwar S. A cross sectional study of vaccine wastage assessment in a primary health care setting in rural central India. Sch J App Med Sci. 2017:3411-15.

35. DeRoeck D, Wang SA. Principles and considerations for adding a vaccine to a national immunization programme: from decision to implementation and monitoring. World Health Organization; 2014. http://apps.who.int/iris/bitstream/10665/111548/1/9789241506892_eng.pdf Accessed on 12 July 2019

36. Jaillard P. Immunization session attendance, vaccine wastage and coverage. 2009:11. https://www.jhsph.edu/ivac/wpcontent/uploads/2018/05/Jaillard-Immunization-session-attendance-wastage-coverage.pdf accessed. Accessed on 12 July 2019

37. WHO | Controlled temperature chain (CTC). WHO. http://www.who.int/immunization/programmes_systems/supply_chain/ctc/en/ 2018. Accessed on 12 July 2019

38. WHO. Controlled 2017-2020. WHO; 2017.

https://www.who.int/immunization/programmes_systems/supply_chain/ctc_strategic_roadmap_priority_vaccines.pdf?ua=1 Accessed on 17 August 2019

\section{Tables}

Due to technical limitations, table 3, 5 and 6 are only available as a download in the Supplemental Files section.

\section{Figures}

1a)

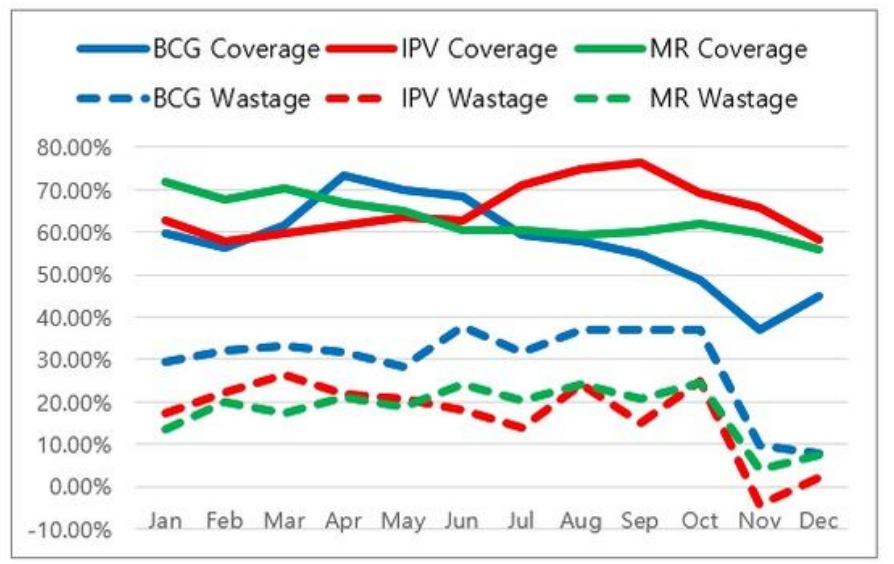

1b)

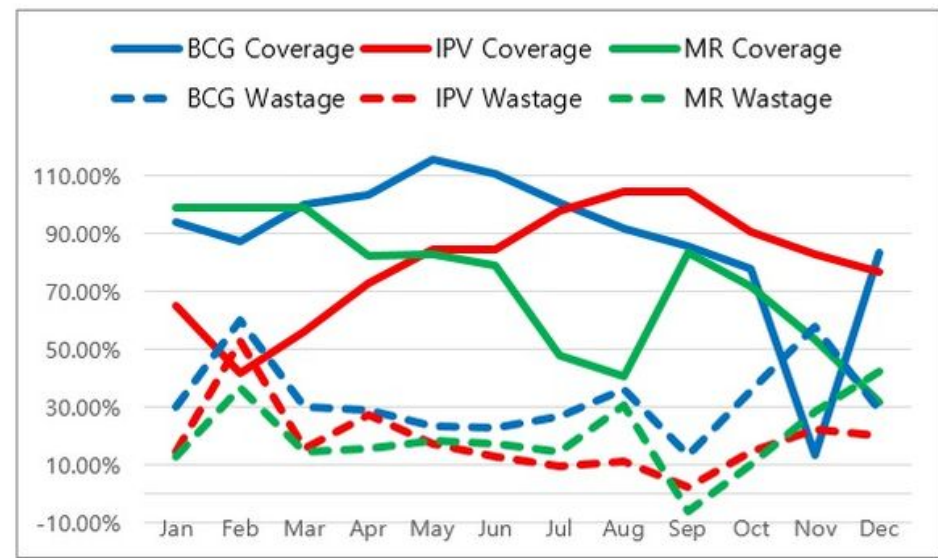

\section{Figure 1}

Variations between vaccination coverage and vaccine wastage for BCG, IPV and MR in 2016 (1a) and 2017 (1b) Note: The relationship between vaccination coverage and vaccine wastage rates for BCG, IPV, and MR in the Littoral Region during 2016 (1a) and 2017 (1b). The lines in blue, red, and green represent the $B C G$, IPV, and MR, respectively. Dotted lines show wastage rates for each vaccine. The $y$-axis shows the vaccine wastage and vaccination coverage rates in percentages. The $\mathrm{x}$-axis shows the monthly breakdown of 2016 and 2017.

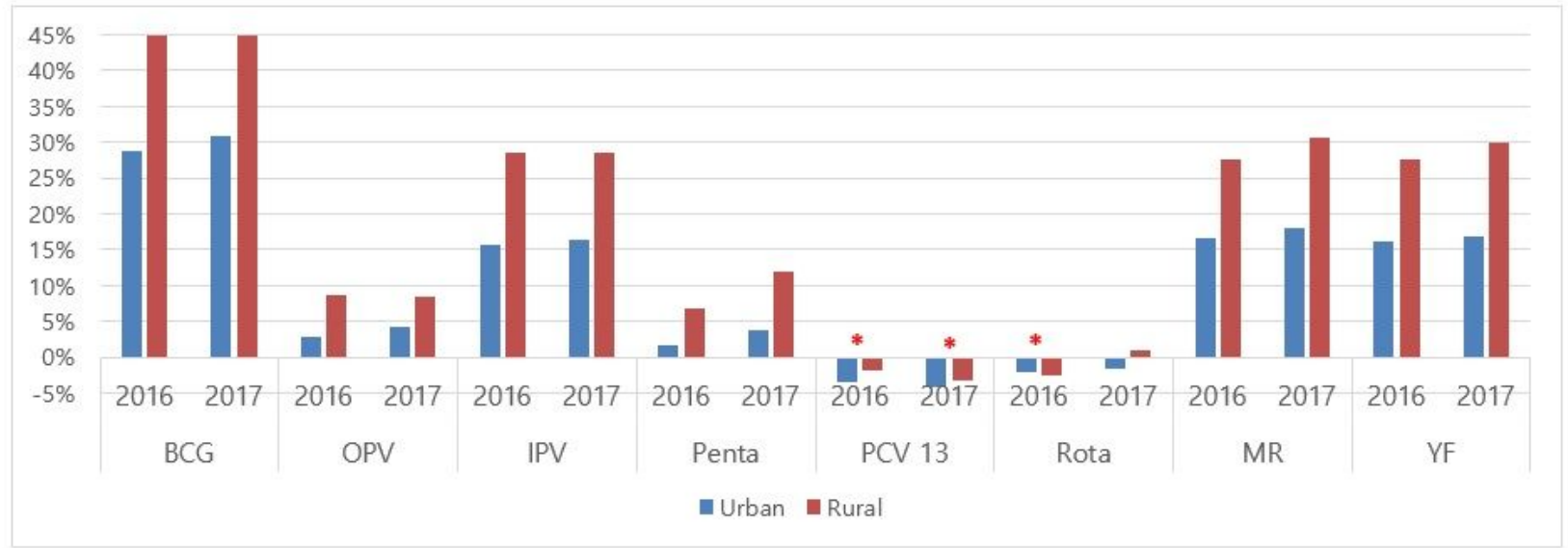

Figure 2 
Vaccine wastage comparing rural and urban health districts in 2016 and 2017 Note: Vaccine wastage rates (VWR, y-axis) in urban and rural health districts are shown as blue and red bars. Significant differences in VWR were observed between urban and rural areas for all vaccines in both 2016 and 2017 , except for the single-dose PCV and rotavirus vaccine, with statistically insignificant findings (marked in red asterisk $\left(^{*}\right)$ ).

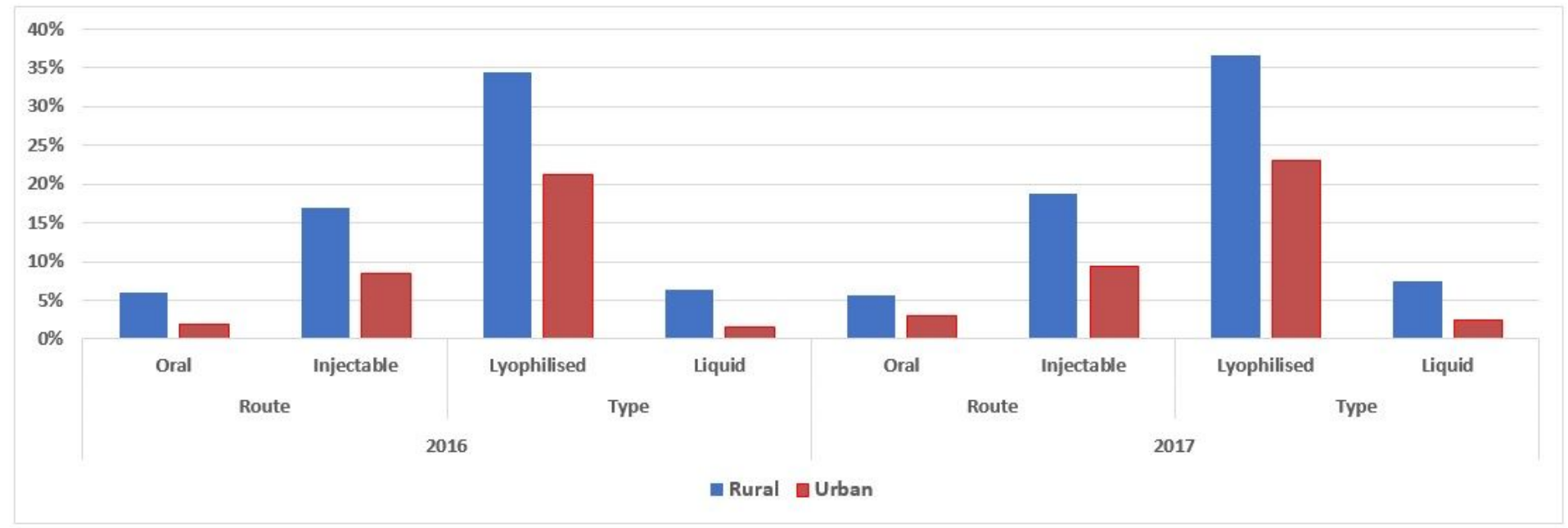

Figure 3

Vaccine wastage rates for different categories of vaccines comparing rural and urban health districts Note: Comparative analysis of the vaccine wastage rates (y-axis) in rural and urban health districts are presented as blue and red bars. Vaccines investigated are categorized according to the route of administration, such as oral (OPV and rotavirus vaccine) or injectable (PCV, pentavalent, BCG, IPV, MR, and YF) and types of vaccines such as lyophilised (BCG, MR, and YF) or liquid (OPV, IPV, pentavalent, PCV, rotavirus).

$4 \mathrm{a}$

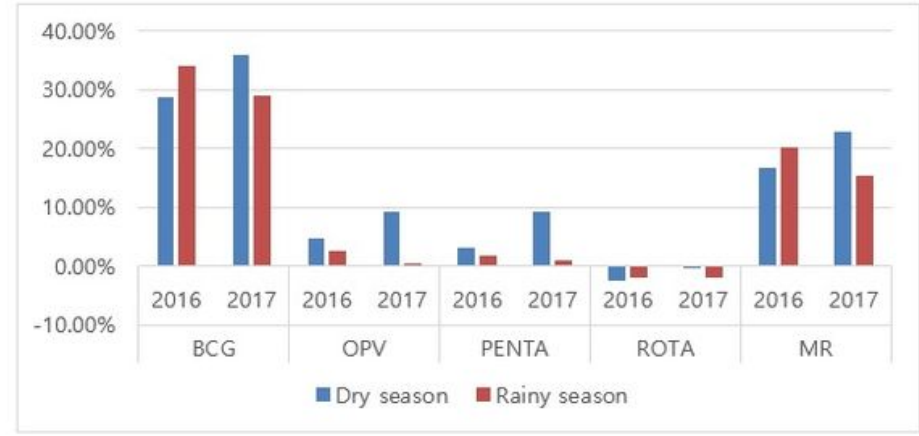

$4 b$

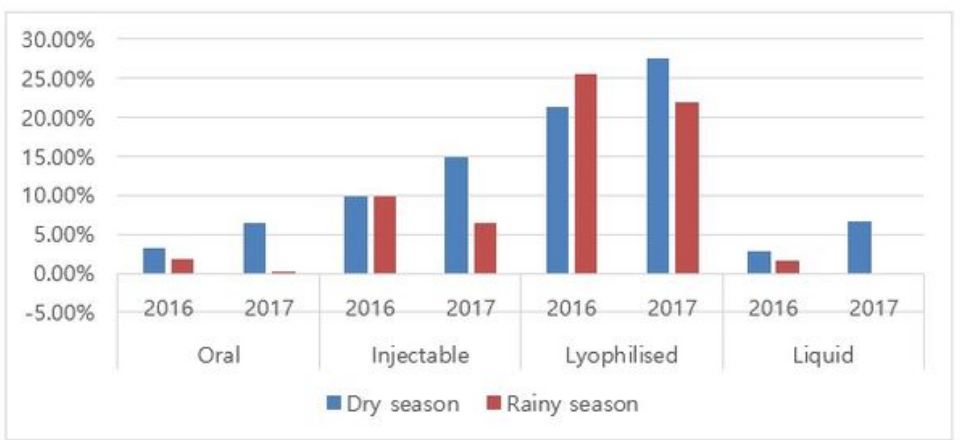

\section{Figure 4}

Vaccine wastage rates for various vaccines in dry and rainy seasons Note: The two figures show different vaccine wastage rates (VWR) for various vaccines and vaccine types in the Littoral Region during 2016 and 2017. The y-axis shows the percentage of VWR. The x-axis shows: (4a) different vaccines; and (4b) categories of vaccines, whereby vaccines are grouped by route of administration (oral and injectable) and form (lyophilized and liquid). The blue and red bars indicate the VWR for the dry and rainy seasons, respectively. Overall, the VWRs were higher in the dry season than in the rainy season for all vaccines, except for BCG and MR vaccines and lyophilized vaccines in 2016.

\section{Supplementary Files}

This is a list of supplementary files associated with this preprint. Click to download.

- Tables3.docx

- Tables5.docx

- Tables6.docx 